\title{
Procedure for Fecal Cuticle Analysis of Herbivore Diets
}

\section{E.J. STEVENS, SUSAN J. STEVENS, R.N. GATES, K.M. ESKRIDGE, AND S.S. WALLER}

\begin{abstract}
Abatract
Cuticular imprints of underlying plant tissue which survive ruminant digestion in herbivore feces provide a reliable taxonomic basis for species identification provided they can be adequately prepared for microhistological analysis. Objoctives of this research were to investigate the discernibility of alfalfa (Medicago sativa L.) cuticle in sheep feces and document a procedure for fecal cuticle analyais. A completely random design with 4 replications was used with a split-plot arrangement of treatments. Diet treatments were applied to whole-plots and fecal preparation techniques were applied to subplots. Mature wethers were fed diets containing 25, 50, or $75 \%$ prebloom alfalfa hay with vezetative indiangrass [Sorghastrum nutens (L.) Nash] hay. A fecal cuticle procedure was described which established a linear relationship between dietary and fecal alfalfa contents. Under conditions where species characterized by fragile cuticle (such as alfalin) are part of the dietary intake and diet is low in woody species, cuticle procedures may represent an alternative method for dietary composition analysis. An epidermal preparatory technique used in conjunction with fecal cuticle procedures did not establish a linear relationship between dietary and fecal alfalín contents.
\end{abstract}

Key Words: microhistological, legumes, epidermis, forbs

Analytical procedures for the microhistological examination of fecal epidermal material described by Sparks and Malechek (1968) and modified by Holechek (1982) are widely used in North America for determining the botanical composition of herbivore diets. Plant epidermal material of certain species was, however, more susceptible to losses during digestion (Vavra et al. 1978, Vavra and Holechek 1980, McInnis et al. 1983) and/or sample preparation (Marshall and Squires 1979, Vavra and Holechek 1980, Holechek 1982, Samuel and Howard 1983) than other species. Holechek and Gross (1982) emphasized the importance of systematic training and evaluation for observers as an aid to improved accuracy and precision.

The waxy cuticle of plants carries a permanent imprint of underlying epidermal characteristics which survives ruminant digestion

Authors were, at the time of research, graduate research assistants (Dep. of Agronomy); consultant (Biometrics and Information Systems Center); and professor (Dep. of Agronomy), Univ. of Nebraska, Lincoln 68583. Dr. E.J. Stevens is currently an agronomist with the International Maize and Wheat Improvement Center (CIMMYT), Londres 40, Apdo. Posta 6-641,06600 Mexico, D.F., Mexico. Dr. R.N. Gates is forage agronomist with the Louisiana Agricultural Experiment Station at the Iberia Research Station, P.O. Box 466, Jeanerette 70544.

The authors wish to thank the Univ. Animal Science Department for animals and facilities.

Contribution from the Nebraska Agr. Exp. Sta., Lincoln, NE. Published as Paper No. 7889, Journal Series.

The authors wish to thank the Univ. Animal Science Department for animals and facilities.

Manuscript accepted 5 June 1986.
(Regal 1960, Monson et al. 1972), thereby providing a reliable taxonomic basis for species identification (Metcalf and Chalk 1950, Metcalf 1960). Rogerson et al. (1976) developed a preparatory technique for fecal cuticle analysis. Acid maceration, sodium hypochlorite $(\mathrm{NaOCl})$, and sodium hydroxide $(\mathrm{NaOH})$, however, used separately on sheep feces and in conjunction with the Sparks and Malechek (1968) procedure for fecal cuticle preparation, destroyed a majority of the cuticular remains of sweet vernal (Anthoxanthum odoratum L.) and white clover (Trifolium repens L.) (Stevens 1977). Holechek (1982) indicated that sodium hydroxide and bleach used as clearing agents may result in the destruction of some plant materials. Distribution of cuticular fragments presented for identification beneath rectangular coverslips was not random (Stevens 1977). Apparently differences in surface tension between cuticle fragments of different species caused some to be sorted towards the outer extremitics of the coverslip. Frequency sampling for microscopic analysis of botanical composition (Sparks and Malechek 1968) would require a random distribution (Fracker and Brischle 1944, Johnson 1982).

Fecal cuticle analysis may enhance the identification of some plant species (e.g., alfalfa) and possibly reduce observer variability when diets do not contain woody species. Procedural modifications which preserve the integrity and/or improve the discernibility of cuticular fragments utilized for microhistological analysis should improve the accuracy with which plant species may be identified in diet residues from herbivore feces. The preparatory procedure described by Sparks and Malechek (1968) was used as a standard for comparing the efficiency of the preparatory procedure proposed by Rogerson et al. (1976) as modified in this study. Objectives of this study were to compare the 2 selected preparatory procedures for fecal cuticle analysis of species with fragile cuticle and develop procedures for slide preparation and data collection for fecal cuticle analysis.

\section{Materials and Methods}

\section{Experimental Design}

A completely random design with 4 replications in a split-plot arrangement was used. Whole-plot and subplot treatments were 3 diets and 2 fecal preparation techniques, respectively. Statistical analyses included pretests of sampling error for microscope technique and basic assumptions of analysis of variance (Neter and Wasserman 1974, Stevens 1985). The cuticle procedure was compared with the epidermal preparation method by considering the preparation $X$ diet interaction in the analysis of variance. Regression analyses described the relationship between observed and actual diet. 


\section{Feeding Trial}

Diets of known composition were hand-fed separately to 12 mature wethers at a level which ensured complete consumption. Feed containers were designed to minimize spillage. Animals (experimental units) were fitted with fecal collection bags, housed indoors, and fed separately in individual metabolism crates. Individual diets contained prebloom alfalfa (Medicago sativa L.) hay (indicator plant for fragile cuticle) and early, vegetative indiangrass [Sorghastrum nutans (L.) Nash] hay which had been ground through a $7.5-\mathrm{cm}$ screen using a tub grinder. Diets averaged 24.1, 48.7 , and $74.1 \%$ alfalfa (\% dry matter).

Each diet was randomly assigned to 4 wethers and fed once daily. Trace mineralized salt $(5 \mathrm{~g})$ was added to the diet daily, and water was available continuously. A 5-day sampling period was preceded by a 12-day feeding period during which animals received respective dietary treatments. During the sampling period total daily fecal production from individual animals was thoroughly mixed and 4 random subsamples (1 liter each) were taken.

One complete set of fresh fecal samples was selected at random from 1 day of the 5-day sampling period. Samples were prepared for cuticle analysis using epidermal preparatory procedures described by Sparks and Malechek (1968), and a proposed cuticle procedure based on a preparatory technique developed by Rogerson et al. (1976). A pretest conducted using this material demonstrated that the discernibility of fecal cuticle prepared using the epidermal technique was not enhanced by presoaking fecal material in undiluted domestic bleach, and there was no significant difference $(P>0.05)$ between diet determinations of 2 trained observers. Neither additional clearing agents nor blocking observations by observer were considered necessary for this experiment.

\section{Fecal Cuticle Procedure \\ Collection and Storage of Feces}

Fecal samples were collected fresh, ensuring that a hardened mucous covering had not developed. Samples were transported and stored in polyethylene bags containing a small amount of either nonchlorinated tap water or distilled water. No preservatives were used. Samples were stored (and/or transported) for up to 1 week without refrigeration provided samples were drained and clean water added daily. Feces can be drained of excess fluid, sealed in plastic bags, frozen, and stored for up to 1 year.

\section{Sample Preparation}

The preparatory technique for fecal cuticle analysis described by Rogerson et al. (1976) was modified and excluded ethyl alcohol. In the laboratory, 50 -ml grab-samples of fresh fecal material were transferred to a double-layered, fine-meshed (less than 350 microns) nylon digestion bag $(200 \mathrm{ml})$ made from nylon stocking. Samples were submerged in a 20-liter bucket of distilled water held at $29^{\circ} \mathrm{C}$ inside a closed styrofoam box which functioned as an incubator. Heat was provided by a 25 -watt light bulb connected to a household dimmer switch. The temperature inside the box was adjusted using the dimmer and measured with an air thermometer visible from outside the box. Up to 30 samples $(50 \mathrm{ml}$ each) were digested simultaneously with care being taken to submerge material using a lightly weighted mesh placed on top of the samples.

Water was changed daily by placing the bucket in a sink and delivering a gentle stream of distilled water to the bottom of the bucket via a flexible rubber hose. Excess water was allowed to run to waste until it was no longer discolored. Bags were gently agitated in the water bath while the water was being changed. Careless handling of fecal bags (e.g., by squeezing) resulted in a reduction in cuticle particle size and loss of clarity of the epidermal imprint on the cuticle.

This daily routine was continued until the water bath was no longer discolored after 24 hours of incubation, usually after 10 to 12 days. Optimum digestion was always associated with a "sweet" aroma, in contrast to a "sour" aroma associated with a putrifying condition. If a putrifying condition occurred the water was changed immediately and reinoculated with fresh fecal material. After digestion and during analysis, the bucket of fecal material was stored in a refrigerator at $2-3^{\circ} \mathrm{C}$ for $1-14$ days and the water changed daily using the routine described above.

Fecal particles having dimensions larger than 750 microns or smaller than 350 microns were discarded since they could not be reliably identified using existing procedures for fecal cuticle analysis. Immediately prior to microscopic analysis, a bag of fecal material was opened and two $13-\mathrm{ml}$ subsamples were transferred, using a perforated seamless nickel cone $(38-\mathrm{mm}, 60$-degree-angle filter paper holder), to a 750-micron sieve. This sieve was held at a 45-degree angle above, but in contact with, a horizontal 350micron sieve. By delivering a gentle stream of distilled water to the underside of the larger sieve, fecal material smaller than 750 microns was washed onto the surface of the lower sieve. Undersized particles were subsequently washed from the 350 -micron sieve held at a 45-degree angle as described for the 750-micron sieve. Fecal material with a particle size range of 350 to 750 microns was retained on the 350-micron sieve as a uniformly sized, representative subsample. This material was washed into a petri dish $(100 \times 15 \mathrm{~mm})$ by applying a gentle stream of distilled water to the lower side of the sieve. The petri dish containing fecal material was topped off with distilled water then set aside for $\mathbf{2 0}$ minutes.

\section{Slide Preparation}

Random 1-ml aliquots (subsamples) of cuticular material recovered from the fecal cuticle preparatory procedure and held in the petri dish were transferred separately to standard microscope slides. An 8-cm length of glass tubing (5-mm inside diameter) fitted with a rubber eyedropper was used, which maintained a column of suspension. Care was taken to sample vertically through the entire depth of cuticular material held in the petri dish since heavier particles tended to settle out first. A minimum of 5 separate aliquots from each petri dish were mounted separately on standard microscope slides and covered with 18-mm-diameter circular coverslips. Circular coverslips greatly improved the uniformity of particle distribution but did not completely eliminate the sorting effect. Additional distilled water was either added to or removed from a slide using a paper tissue, thereby adjusting particle density under the coverslip. Where necessary, additional slides were prepared to facilitate 250 positive identifications per treatment.

Small aliquots of fecal cuticle material recovered from the epidermal preparatory procedure were mounted on microscope slides using Hoyer's and Hertwig's solutions and ovendried as outlined in the Sparks and Malechek (1968) technique. Slides were covered with a circular coverslip.

\section{Botanical Analysis}

Slides prepared from both procedures were evaluated using a common technique. Fecal particles were identified by species, and as leaf or stem by 2 trained observers (S.J. and E.J. Stevens) using photomicrographs and camera lucida drawings prepared from permanent reference slides (S.J. Stevens 1985, unpublished) as identification aids. Each microscope slide was traversed once laterally at $100 \mathrm{X}$ magnification. Identifications were made within a belt transect of successive, but not overlapping, fields of view stretching across the diameter of the coverslip. This procedure minimized the problem associated with the lack of random distribution of particles necessary for frequency sampling. Positive identification was attempted on all particles originating within a particular field of view, a diameter of $1.8 \mathrm{~mm}$ at $100 \mathrm{X}$ magnification. Occasional confirmations were necessary at $400 \mathrm{X}$ magnification after which the observer returned to $100 \mathrm{X}$ magnification before continuing to traverse a slide. Positive identifications per subsample were summed by species and plant part within species (e.g., leaf or stem). Positively identified components were expressed as a proportion of the total number of positive identifications. This technique of cuticle analysis differs from the counting method (frequency sampling) described by Sparks and Malechek (1968) in 
which the presence of a category of epidermis within a given number of fields was recorded.

\section{Results and Discussion}

The preparation $X$ diet interaction in the analysis of variance was highly significant $(P<0.0001)$ and indicated that the linear effect of alfalfa diet content on fecal cuticle alfalfa was different for the 2 preparatory methods (Fig. 1). The modified cuticle procedure

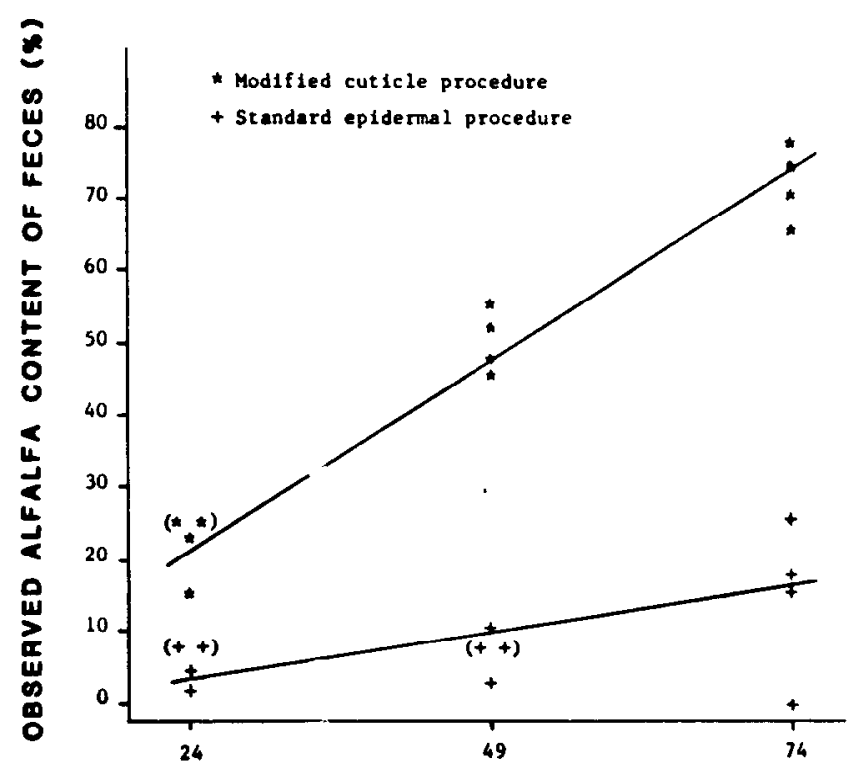

ALFALFA CONTENT OF DIET ( $\%$ )

Fig. 1. Alfalfa content identified in the feces from different diet combinations using epidermal and cuticular procedures.

did not have a slope significantly different from $1(P=0.6361)$, while the epidermal preparatory technique for cuticle analysis had a slope of less than $1(P=0.0001$, slope estimate $=0.1728)$. Such a disparity of slopes indicated that the epidermal preparatory technique was not suitable for fecal cuticle analysis as used in this study. These fecal cuticle data, however, should not be compared directly with recent epidermal studies of Holechek and Valdez (1985b), who used in vitro digestion techniques (Tilley and Terry 1963), or Holechek and Valdez (1985a), who reported that their epidermal techniques accurately determined the alfalfa content of mule deer diet. Analytical techniques were not the same across all 3 studies.

Holechek et al. (1982), Gross et al. (1983) and Holechek and Valdez (1985a) demonstrated observer variability was substantial when microhistological epidermal analysis was used. In our study, however, observer variability was not apparently a major source of variation. The sum of squares attributed to error was only 3-15\% of that of the main effects and interactions, respectively. Blocking data by observer would not have increased the power of this analysis appreciably. In addition, standard errors for fecal cuticle analysis compared favorably with published epidermal data.

This pilot procedural study of fecal cuticle analysis has reintroduced, and tentatively substantiated, a concept of developing alternative procedures for fecal analysis which preclude the need for drying, grinding, acid maceration, and/or the use of clearing and mounting agents, which are jointly suspected of destroying some plant (cuticle) fragments known to survive ruminant diges- tion. Further research is needed to evaluate the suitability of cuticle procedures under a broader range of conditions than those reported here. Treatments should include a broad selection with varying ratios of indigenous and/or introduced species of contrasting digestibility and/or cuticle durability. Techniques are needed to handle fecal fragments which fail to pass through a 750-micron sieve and/or originate from woody species. The impact of fermentation on the composition of plant cuticle during sample preparation has not been researched, nor has the possibility of over representation of dietary components represented by both abaxial and adaxial leaf cuticle. This study does, however, provide a platform for further research on alternative procedures for botanical analysis of herbivore diet.

\section{Literature Cited}

Fracker, S.B., and J.A. Briachle. 1944. Measuring the local distribution of Ribes. Ecology 25:283-303.

Gross, B.D., E. Mahgoub, and J.L. Holechek. 1983. Mastication effects on cattle diet determination by microhistological analysis. J. Range Manage. $36: 475-476$.

Holechek, J.L. 1982. Sample preparation techniques for microhistological analysis. J. Range Manage. 35:267-268.

Holechek, J.L., and B. Gross. 1982. Training needed for quantifying simulated diets from fragmented range plants. J. Range Manage. 35:644-647.

Holechek, J.L., and R. Valdez. 1985. Magnification and shrub stemmy material influences on fecal analysis accuracy. J. Range Manage. 38:350-352.

Holechek, J.L., and R. Valdez. 1985b. Evaluation of in vitro digestion for improving botanical estimates of mule deer fecal samples. J. Mamm. 66:574-577.

Holechek, J.L., M. Vavra, and R.D. Pieper. 1982. Botanical composition determination of range herbivore diets: a review. J. Range Manage. 35:309-315.

Johnson, M.K. 1982. Frequency sampling for microscopic analysis of botanical compositions. J. Range Manage. 35:541-542.

Marshall, J.W., and V.R. Squires. 1979. Accuracy of quantitative methods used for the botanical analysis of esophageal fistuala samples. Trop. Grass. 13:140-148.

McInnis, M.L., M. Vavra, and W.C. Krueger. 1983. A comparison of 4 methods used to determine the diets of large herbivores. J. Range Manage. 36:302-306.

Metcalf, C.R. 1960. Anatomy of the monocotyledons. I. Gramineae. Claredon Press, Oxford.

Metcalf, C.R., and L. Chalk. 1950. Anatomy of the dicotyledons. Vol. 1 and 2. Claredon Press, Oxford.

Monson, W.G., J.B. Powell, and G.W. Burton. 1972. Digestion of fresh forage in rumen fluid. Agron. J. 64:231-233.

Neter, J., and W. Wasserman. 1974. Applied linear statistical models: regression, analysis of variance, and experimental designs. Richard D. Irwin, Inc. Homewood, Ill.

Regal, V. 1960. The evaluation of the quality of pasture grasses by the microscope method. Proc. Eighth Int. Grassland Cong. 1960:522-524.

Rogerson, S.J., E.J. Stevens, and J.G. Hughes. 1976. An improved technique for identification of plant cuticle in animal feces. N.Z. J. Bot. 14:117-119.

Samuel, M.J., and G.S. Howard. 1983. Disappearing forbs in microhistological analysis of diets. J. Range Manage. 36:132-133.

Sparks, D.R., and J.C. Malechek. 1968. Estimating percentage dry weight in diets using a microscopic technique. J. Range Manage. 21:264-265.

Stevena, E.J. 1977. Botanical analysis of sheep diet. A comparison of 3 methods of sheep diet determination and the field application of fecal cuticle analysis. M. Agr. Sci. Thesis, Lincoln College, New Zealand.

Stevens, E.J. 1985. Temperature dependent phenological models for dent corn and popcorn (Zea mays L.). Ph.D. Diss. Univ. Nebraska, Lincoln.

Tilley, J.M.A., and R.H. Terry. 1963. A two-stage technique for the in vitro digestion of forage crops. J. British Grassland Soc. 18:104-111.

Vavra, M., and J.L. Holechek. 1980. Factors influencing microhistological analysis of herbivore diets. J. Range Manage. 33:371-374. 